\title{
Asymmetric Momentum Threshold Effect of Copper Futures Returns on Spot Returns Volatility in London Metals Exchange under High Volatility
}

\author{
Yeong Jia Goo, Chih Chang Chen* \\ Department of Business Administration, National Taipei University, Taiwan \\ Email: *ccchen@gm.cute.edu.tw
}

How to cite this paper: Goo, Y.J. and Chen, C.C. (2020) Asymmetric Momentum Threshold Effect of Copper Futures Returns on Spot Returns Volatility in London Metals Exchange under High Volatility. Modern Economy, 11, 51-61.

https://doi.org/10.4236/me.2020.111006

Received: November 30, 2019

Accepted: January 10, 2020

Published: January 13, 2020

\section{Copyright $\odot 2020$ by author(s) and} Scientific Research Publishing Inc. This work is licensed under the Creative Commons Attribution International License (CC BY 4.0).

http://creativecommons.org/licenses/by/4.0/

\section{(c) (i) Open Access}

\begin{abstract}
This paper discusses the asymmetric momentum threshold effect of copper futures returns on spot returns volatility in the London Metal Exchange. Referring the Threshold Autoregressive (TAR) and Momentum Threshold Autoregressive (MTAR) models, this study utilizes a Hybrid MTAR-GARCH model to test the asymmetric momentum threshold effects of LME copper futures returns on spot returns volatility. It is revealed that there are indeed asymmetric momentum threshold effects of LME copper futures returns on spot returns volatility. This finding would be beneficial to financial decision-making concerning copper price hedging, arbitrage and investment amidst high volatility market conditions.
\end{abstract}

Keywords

Returns, Volatility, Asymmetric Effect, Hybrid MTAR-GARCH

\section{Introduction}

Copper is a malleable metal with high thermal and electrical conductivity. It is widely used in infrastructure projects such as power electronics, architecture and transportation. As a result, the copper market has become an investment instrument and entity for related industries and financial professionals, and the impact of copper price fluctuations on the global economy is often discussed.

Gao and Wang [1] utilized the asymmetric ARMAX-GARCH model to test basis volatilities and found that London Metal Exchange's (LME) six metal futures contract prices (aluminium, copper, lead, tin, zinc and nickel) and 
NYMEX's copper futures price have strong and negative asymmetries, whereas such asymmetries were not revealed in terms of NYMEX's gold and silver futures prices. Zhu et al. [2] used the VEC model and ECARCH model and found that the exchange rate of RMB against US dollars, foreign exchange reserves and broad monetary supply exerted short-term influence on three-month copper futures prices of Shanghai $(\mathrm{SH})$, with broad monetary supply exerting long-term influence. Zhang and $\mathrm{Tu}$ [3] utilized the ARJI-GARCH model and found that the fluctuations and jumps of international oil prices have a more significant impact on China's copper prices than aluminium prices. $\mathrm{Wu}$ and $\mathrm{Hu}$ [4] studied the volatility clustering and volatility correlation of China's copper, aluminium and zinc prices and found that the three metals' prices fluctuated substantively and had dynamic correlations during the financial crisis.

Marbrouk [5] utilized five models, namely the Integrated GARCH, GRACH, FIGARCH, FIAPARCH and hyperbolic GARCH models, revealing that LME's copper, aluminium, nickel and zinc prices showed volatility persistence, clustering and asymmetry, and put forth hedging strategies via VAR assessment. Wang and Chang [6] used the VAR model to reveal that house price index (HPI) exerted significant influences on LME copper prices, ISM Purchasing Managers' Index and S\&P 500 Index. The above studies mainly focus on the research results of subjects concerning the correlations between copper prices and oil, metals, the overall economic indicators, volatility, etc., instead of discussing fluctuations under high volatility market conditions.

Based on cost of carry principles, the price variance between spots and futures could be regarded as non-equilibrium adjustment conditions. Deduced from Fama and French [7], Gao and Wang [1] found that the impacts of short-term demand caused major metal price changes for spots, rather than for futures. Furthermore, the increase in spots price volatility was larger than that of futures. Chatrath et al. [8] found that, under high volatility, lead-lag asymmetry could be observed against index futures and spot markets, where the returns volatilities are positively correlated.

Traditionally, the GJR-GARCH model is used to investigate the asymmetric residual effects on conditional volatility [9] [10] [11] [12] [13]. The shortcoming of such a model is that the model distinguishes asymmetric volatility behaviour based on positive or negative residuals, i.e., using zero as a threshold. However, the zero-threshold model might not be necessarily the most suitable one. Thus, scholars have developed "non-zero-threshold" TAR and MTAR models [14] [15] [16]. Recently, Goo and Shih [17] utilized Hybrid MTAR-GARCH (HMTAR) model to simultaneously observe two random thresholds of residuals and residual differences, and found that, under highly volatile securities market conditions, the basis volatility of index futures did exhibit asymmetric TAR and MTAR phenomena.

By using HMTAR-GARCH model, this study intends to test the asymmetric effects and nonlinear momentum threshold effects of London's copper futures returns on spot returns volatility under highly volatile market condi- 
tions. The findings would improve the forecast of copper spot volatility and arbitrage decision-marking under high volatility. The rest of paper is organized as follows. Section 2 describes data and research methodology, including linear and non-linear unit root tests, ARCH effect tests, GJR-GARCH, and HMTAR-GARCH model development and estimation procedure. Section 3 shows the empirical research findings. Section 4 summarizes the conclusion and suggestions.

\section{Research Methodology}

\subsection{The Source of Data}

The daily data were London Metal Exchange (LME) copper spots and futures closing prices. The sample period ranges from Jan. 2, 1997 to Dec. 31, 2018. A total of 5605 samples (including from the period of financial crisis) from LME were collected.

Firstly, the returns of the LME copper spots and futures are defined as follows:

$$
\begin{aligned}
& R E T_{t}=\ln \left(S P R_{t} / S P R_{t-1}\right)=\ln \left(S P R_{t}\right)-\ln \left(S P R_{t-1}\right) \\
& F R_{t}=\ln \left(F P R_{t} / F P R_{t-1}\right)=\ln \left(F P R_{t}\right)-\ln \left(F P R_{t-1}\right)
\end{aligned}
$$

$S P R_{t}$ represents the copper spot prices at time $t, R E T_{t}$ represents the copper spot returns. $F P R_{t}$ represents the copper futures prices, $F R_{t}$ represents the copper futures returns. Referring to the research of Baur and McDermott (2010), the period of financial crisis is defined from Oct. 29, 2007 to Nov. 20, 2008, which is the ending day when the International Monetary Fund (IMF) signed the USD 2.1 billion Economic Stabilization Program with Iceland.

\subsection{Unit-Root Test}

\subsubsection{Augmented Dickey-Fuller (ADF) Unit Root Test}

In 1981, Dickey-Fuller [18] suggested to augment the DF unit root test by taking into consideration the serial correlation of residual terms as well as incorporating more previously measured value of error terms as explanatory variables, so that the impacts of the serial correlation of the error terms could be removed, and subsequently carrying out the hypothetical test on " $\lambda$ " after having assessed the model via OLS.

1) The random walk model without drift or trend components

$$
\Delta y_{t}=\lambda y_{t-1}+\sum_{i=1}^{k} \delta_{i} \Delta y_{t-i}+\varepsilon_{t}
$$

2) The random walk model with drift but no trend component

$$
\Delta y_{t}=\alpha_{0}+\lambda y_{t ? 2}+\sum_{i=1}^{k} \delta_{i} \Delta y_{t-i}+\varepsilon_{t}
$$

3) The random walk model with drift and trend components

$$
\Delta y_{t}=\alpha_{0}+\gamma_{t}+\lambda y_{t,-}+\sum_{i=1}^{k} \delta_{i} \Delta y_{t-i}+\varepsilon_{t}
$$


The null hypothesis is $H_{0}: \lambda=0$ (there is a unit root, time series data are not stationary).

The alternative hypothesis is $H_{1}: \lambda \neq 0$ (there is no unit root, time series data are stationary).

\subsubsection{Phillips-Perron (PP) Unit Root Test}

In 1988, Phillips and Perron [19] utilized the non-parametric statistics of central limit theorem in function forms to simultaneously examine whether the residual terms have autocorrelation and heteroscedasticity. The PP unit root model for testing the random walk model with drift and trend component is as follows:

$$
y_{t}=\alpha+\sigma\left(t-\frac{T}{2}\right)+\varphi y_{t-1}+u_{t}
$$

The null hypothesis is $H_{0}=y_{t-1}+u_{t}$.

Where the $\alpha, \sigma$ and $\varphi$ are regression coefficients test when $\alpha=\sigma=0$ and $\varphi=1$, if there is a unit root, the time series data are not stationary; otherwise the time series data would be stationary and the null hypothesis would be rejected.

\subsubsection{Nonlinear Unit Root Test (KSS Unit Root Test)}

$\mathrm{ADF}$ and PP unit root tests are based on the assumptions that the series is linear, and therefore excludes the nonlinear series which might cause low statistical power. In light of this, Kapetanios et al. [20] put forth the nonlinear structured unit root test, which mainly uses a nonlinear ESTAR model to examine whether the time series data are stationary. The KSS unit root test is as follows:

$$
\Delta y_{t}=\gamma y_{t-1}\left[1-\exp \left(-\theta y_{t-1}^{2}\right)\right]+\varepsilon_{t}
$$

The null hypothesis is $H_{0}: \theta=0$ (There is a unit root, the time series data are not stationary). $\Delta y_{t}$ is the rate of change of parameter coefficient, $\varepsilon_{t}$ is the error term, $\theta$ is the conversion rate of ESTAR model. Since $\gamma$ could not be verified under KSS unit root null hypothesis, the formula (7) is re-calculated using Taylor series expansions. After first asymptotic expansion, the model is as follows:

$$
\Delta y_{t}=v y_{t-1}^{3}+\text { error }
$$

In response to the error series correlation, the lagged variable $\Delta y_{t}$ is added into the following model:

$$
\Delta y_{t}=v y_{t-1}^{3}+\omega_{1} \Delta y_{t-1}+\omega_{2} \Delta y_{t-2}+\cdots+\omega_{p} \Delta y_{t-p}+\text { error }
$$

The null hypothesis is $H_{0}: v=0$, there is a unit root, the time series data are not stationary; otherwise the time series data would be stationary, and the null hypothesis would be rejected.

\subsubsection{The Conventional TAR and MTAR Models}

Enders and Granger [21] and Enders and Siklos [15] incorporated threshold and momentum auto regression to test whether there is a long-term equilibrium. The TAR model is: 


$$
\begin{gathered}
y_{t}=\beta_{0}+\beta_{1} X_{t}+u_{t} \\
\Delta u_{t}=I_{t} \rho_{1} u_{t-1}+\left(1-I_{t}\right) \rho_{2} u_{t-1}+\sum_{i=1}^{k} \gamma_{i} \Delta u_{t-1}+\varepsilon_{t}
\end{gathered}
$$

where $\varepsilon_{t}$ is white noise, $\beta_{0}, \beta_{1}, \rho_{1}, \rho_{2}$ and $\gamma_{i}$ are regression coefficients, $\tau$ is the unknown threshold value simulation:

$$
I_{t}= \begin{cases}1 & \text { if } u_{t-1} \geq \tau_{1} \\ 0 & \text { if } u_{t-1}<\tau_{1}\end{cases}
$$

MTAR is used to adjust the process. The first residual difference series is:

$$
\begin{gathered}
\Delta u_{t}=M_{t} \rho_{1} u_{t-1}+\left(1-M_{t}\right) \rho_{2} u_{t-1}+\sum_{i=1}^{k} \gamma_{i} \Delta u_{t-1}+\varepsilon_{t} \\
M_{t}= \begin{cases}1 & \text { if } \Delta u_{t-1} \geq \tau_{2} \\
0 & \text { if } \Delta u_{t-1}<\tau_{2}\end{cases}
\end{gathered}
$$

The conventional approach uses Formula (11) and (13) to test separately, thus it is unable to simultaneously test two effects. The following section would use the hybrid MTAR-GARCH model to examine when the residuals and differences are lower than thresholds, whether there are asymmetric and nonlinear incremental effects.

\subsubsection{The Hybrid MTAR-GARCH Model}

Finally, this study refers to the hybrid MTAR-GARCH model adopted by Goo and Shih [17], which proposes the average and variance formula, and takes into account the variable of simulation during the financial crisis. The empirical models are as follows:

$$
\begin{aligned}
R E T_{t}= & \zeta_{0}+\zeta_{1} R E T_{t-1}+\zeta_{2} F R_{t-1}+\zeta_{3}\left(I_{t} F R_{t-1}\right)+\zeta_{4}\left(M_{t} F R_{t-1}\right) \\
& +\zeta_{5}\left(D_{1} F R_{t-1}\right)+\zeta_{6}\left(D_{1} I_{t} F R_{t-1}\right)+\zeta_{7}\left(D_{1} M_{t} F R_{t-1}\right)+\varepsilon_{t} \\
h_{t}=\theta_{0} & +v_{1} h_{t-1}+\theta_{1} \varepsilon_{t-1}^{2}+\eta_{1} F R_{t-1}+\eta_{2}\left(I_{t} F R_{t-1}\right)+\eta_{3}\left(M_{t} F R_{t-1}\right) \\
+ & \eta_{4} D_{1} F R_{t-1}+\eta_{5}\left(D_{1} I_{t} F R_{t-1}\right)+\eta_{6}\left(D_{1} M_{t} F R_{t-1}\right)
\end{aligned}
$$

where,

$$
\begin{gathered}
I_{t}= \begin{cases}1 & \text { if } \varepsilon_{t-1} \geq \tau_{1} \\
0 & \text { if } \varepsilon_{t-1}<\tau_{1}\end{cases} \\
M_{t}= \begin{cases}1 & \text { if } \Delta \varepsilon_{t-1} \geq \tau_{2} \\
0 & \text { if } \Delta \varepsilon_{t-1}<\tau_{2}\end{cases}
\end{gathered}
$$

where $R E T_{t}$ is the copper spot returns, $F R_{t-1}$ is the copper futures returns, $D_{1}$ is the variable of simulation during the financial crisis. Coefficients $\eta_{2}$ and $\eta_{5}$ test whether the residuals have positive or negative asymmetric TAR effect; coefficients $\eta_{3}$ and $\eta_{6}$ test whether the residual differences have a nonlinear MTAR effect. The residual term $\varepsilon_{t}$ does not have autocorrelation and has white noise feature. Moreover, when $\tau_{1}=\tau_{2}=0$, Models (15) and (16) are similar to the GJR-GARCH model. 


\subsubsection{Research Hypotheses}

When a stock market is under overwhelming sell-off pressure (i.e. under high volatility), short-term futures would be under higher pressure to sell, and traders could sell the futures prior to the upcoming stock price drop. As a result of the increasing pressure to sell short-term futures, the futures prices would drop more rapidly, leading to augmented price fluctuations. Speculators and arbitrage investors could sell spots and buy futures to obtain additional premiums.

Therefore, if the previous residuals $\left(\varepsilon_{t-1}\right)$ are lower than certain thresholds, it suggests that the rate of futures price drops was faster than expected and caused the following trading day to have larger volatility; and if the previous residual differences $\left(\Delta \varepsilon_{t-1}\right)$ are lower than certain thresholds, it reveals that the market is becoming highly unexpected, volatility is likely to increase even more. This study refers to the assertions of Gao and Wang [1] and Goo and Shih [17], exploring whether the London Metal Exchange's copper spots and futures, would experience the same trends as in the stock market under high volatility. Therefore, this study examines the following hypotheses:

Hypothesis 1: During the Financial crisis, when the pre-Financial crisis residual is lower than its threshold $\tau_{1}$, the impact of future returns on spots volatility is greater (The TAR effect, i.e., $\eta_{5}<0$ ).

Hypothesis 2: In the financial crisis period, when the pre-financial crisis residual difference is lower than the momentum threshold $\tau_{2}$, the impact of future returns on spots volatility is greater (The MTAR effect, i.e., $\eta_{6}<0$ ).

Hypothesis 3: The MTAR effect has a greater negative impact compared to the TAR effect during volatile market condition, i.e., $H_{3-1}: \eta_{6}<\eta_{5}$. Another way to verify the hypothesis is to include non-volatile period, i.e.,

$H_{3-2}: \eta_{3}+\eta_{6}<\eta_{2}+\eta_{5}$.

\section{The Results of Empirical Research}

In Baur and McDermott's [22] study, the financial crisis starting from October 29, 2007 and ending on November 20, 2008. The sample period of this study is from Jan. 2, 1997 to Dec. 31, 2018. A total of 5604 samples were been collected from LME concerning the spot and futures returns on a daily basis (including the data from the financial crisis that lasts 270 days) as shown in Table 1.

The descriptive statistical summary of futures returns (FR) is shown in Table 2.

Compared to other periods, $F R$ has a larger standard deviation during the Financial crisis, with a negative average returns. Then, the ADF, PP and KSS unit root tests on RET series are examined. In Table 3, the results show that the series are stationary regardless of lags 5,10 or 20 . As shown in Table 4, the heteroscedasticity test shows that there exist ARCH effects regardless of lags 1, 5 and 10.

The study then adopts a 3-tier computational model. Model 1 is the ARCH model without threshold. Model 2 is the $\operatorname{GJR}-\operatorname{GARCH}(1,1)$ model with the TAR threshold $\left(\tau_{1}\right)$ and the MTAR threshold $\left(\tau_{2}\right)$ set as 0 . Model 3 is the HMTAR model with random $\tau_{1}$ and $\tau_{2}$. The goodness of fit test of the models 
adopts AIC principles [23], SBC principles [24] and Log Likelihood function (LL), when the AIC and SBC test results are smaller, the LL results are larger, it suggests that the independent variables of the model are able to explain the dependent variables. Based on the statistical results of the 3-tier computational model, the HMTAR-GARCH model has good model fit, the GARCH model has a slightly less goodness of fit, confirming that the HMTAR-GARCH model is a better fit than other models (Table 5 ).

Hypothesis 1 and Hypothesis 2 are supported, since $\eta_{5}$ and $\eta_{6}$ are negative significantly. The WALD tests show that the null hypothesis $H_{3-1}: \eta_{6}<\eta_{5}$, Chi-square $=0.67915(p=0.4099)$ fails to reach the significant level; while the null hypothesis $H_{3-2}:\left(\eta_{3}+\eta_{6}\right)<\left(\eta_{2}+\eta_{5}\right)$, Chi-square $=4.5936(p=0.0321)$ reaches the significant level. Hence Hypothesis 3 is supported.

Table 1. Segmented period from January 2, 1997 to December 31, 2018.

\begin{tabular}{ccc}
\hline & Period & Trading Days \\
\hline Pre-Financial Crisis & January 2, 1997-October 26, 2007 & 2779 \\
Financial Crisis & October 29, 2007-November 20, 2008 & 270 \\
Post-Financial Crisis & November 21, 2008-December 31, 2018 & 2555 \\
Overall Observed Time & January 2, 1997-December 31, 2018 & 5604 \\
\hline
\end{tabular}

Table 2. The descriptive statistics of copper futures returns (FR).

\begin{tabular}{ccccc}
\hline & Mean & Standard Deviation & Minimum & Maximum \\
\hline Pre-Financial Tsunami & 0.002 & 0.644 & -4.961 & 4.77 \\
Financial Tsunami & -0.124 & 1.14 & -4.517 & 5.16 \\
Post-Financial Tsunami & 0.009 & 0.682 & -3.406 & 3.882 \\
Overall Observed Time & 0.694 & 0.008 & -4.961 & 5.16 \\
\hline
\end{tabular}

Table 3. The results of linear and nonlinear unit root tests.

\begin{tabular}{cccc}
\hline \multirow{2}{*}{ lags } & ADF & PP & KSS \\
\cline { 2 - 4 } & t-Statistic & t-Statistic & t-Statistic \\
\hline 5 & $-80.2347^{\star * *}$ & $-80.2347^{\star * *}$ & $-14.1395^{\star * *}$ \\
10 & $-21.1022^{* * *}$ & $-80.1512^{\star * *}$ & $-10.8130^{\star * *}$ \\
20 & $-14.6596^{* * *}$ & $-80.0157^{\star * *}$ & $-8.7144^{* * *}$ \\
\hline
\end{tabular}

Notes: ${ }^{*},{ }^{*}$ and ${ }^{* * *}$ indicate $10 \%, 5 \%$ and $1 \%$ significant level.

Table 4. The results of heteroscedasticity tests.

\begin{tabular}{ccc}
\hline Heteroscedasticity Test(lags) & F-Statistic Test & Chi-Square Test \\
\hline ARCH(1) & $430.1581^{\star * *}$ & $399.6207^{\star * \star}$ \\
ARCH(5) & $199.369^{\star * *}$ & $846.9598^{\star * \star}$ \\
ARCH(10) & $120.7771^{\star * *}$ & $994.9198^{\star * \star}$
\end{tabular}

Notes: ${ }^{*}{ }^{* *}$ and ${ }^{* * *}$ indicate $10 \%, 5 \%$ and $1 \%$ significant levels. 
Table 5. 3-tier computational results (5604 obs.).

\begin{tabular}{|c|c|c|c|c|c|c|c|c|c|}
\hline \multirow{4}{*}{ RET } & \multicolumn{3}{|c|}{ Model 1} & \multicolumn{3}{|c|}{ Model 2} & \multicolumn{3}{|c|}{ Model 3} \\
\hline & \multicolumn{3}{|c|}{$(\mathrm{ARCH})$} & \multicolumn{3}{|c|}{ (GJR-GARCH) } & \multicolumn{3}{|c|}{ (HMTAR-GARCH) } \\
\hline & \multicolumn{3}{|c|}{ (No Threshold) } & \multicolumn{3}{|c|}{$\left(\tau_{1}=\tau_{2}=0\right)$} & \multicolumn{3}{|c|}{$\left(\tau_{1}=-1.4202 ; \tau_{2}=1.1655\right)$} \\
\hline & \multirow[t]{2}{*}{ Coeff. } & \multicolumn{2}{|c|}{ t-stat } & Coeff. & \multicolumn{2}{|l|}{ t-stat } & Coeff. & \multicolumn{2}{|c|}{ t-stat } \\
\hline \multicolumn{9}{|c|}{ Mean Equation: } & \\
\hline$\zeta_{0}$ & 0.0041 & 0.5877 & & 0.0044 & 0.6355 & & 0.0049 & 0.7071 & \\
\hline$\zeta_{1}$ & -0.4212 & -26.7077 & $* * *$ & -0.4232 & -26.9314 & $* * *$ & -0.4093 & -26.0514 & $=* * *$ \\
\hline$\zeta_{2}$ & 0.5819 & 38.8885 & $* * *$ & 0.5904 & 30.0805 & $* * *$ & 0.4208 & 5.662 & $* * *$ \\
\hline$\zeta_{3}$ & -0.2164 & -3.4728 & $* * *$ & 0.0094 & 0.3615 & & 0.1793 & 2.4352 & $* *$ \\
\hline$\zeta_{4}$ & & & & -0.0309 & -1.1802 & & -0.2639 & -4.8958 & $* * *$ \\
\hline$\zeta_{5}$ & & & & 0.0322 & 0.5865 & & 0.0164 & 0.2747 & \\
\hline$\zeta_{6}$ & & & & -0.0792 & -0.6917 & & -0.2375 & -2.9419 & $* * *$ \\
\hline$\zeta_{7}$ & & & & -0.1343 & -1.1317 & & 0.2789 & 1.6334 & * \\
\hline \multicolumn{10}{|c|}{ Variance Equation: } \\
\hline$\theta_{0}$ & 0.0025 & 5.5391 & $* * *$ & 0.0025 & 5.4008 & $* * *$ & 0.002 & 4.8943 & $* * *$ \\
\hline$v_{1}$ & 0.9405 & 217.289 & $* * *$ & 0.9412 & 211.21 & $* * *$ & 0.9466 & 235.8294 & $* * *$ \\
\hline$\theta_{1}$ & 0.053 & 13.6055 & $* * *$ & 0.0525 & 13.2126 & $* * *$ & 0.0488 & 13.2596 & $* * *$ \\
\hline$\eta_{1}$ & -0.0014 & -0.6734 & & -0.0040 & -1.1717 & & -0.1201 & -4.5597 & $* * *$ \\
\hline$\eta_{2}$ & -0.0646 & -3.4636 & $* * *$ & -0.0025 & -0.4837 & & 0.119 & 4.5505 & $* * *$ \\
\hline$\eta_{3}$ & & & & 0.0089 & 1.3767 & * & -0.0012 & -0.0748 & \\
\hline$\eta_{4}$ & & & & -0.0242 & -0.7131 & & 0.0321 & 0.7343 & \\
\hline$\eta_{5}\left(H_{1}\right)$ & & & & -0.0814 & -1.2785 & & -0.0668 & -1.9357 & $* *$ \\
\hline$\eta_{6}\left(H_{2}\right)$ & & & & 0.0297 & 0.6768 & & -0.1366 & -1.6298 & * \\
\hline AIC & -516 & 206 & & -498 & 3721 & & -553 . & 2718 & \\
\hline SBC & -525 & 901 & & -524 & 2416 & & -578 & 6419 & \\
\hline LL & 267 & & & 266. & & & 293.6 & 359 & \\
\hline
\end{tabular}

Notes: ${ }^{*}{ }^{* *}$ and ${ }^{* * *}$ indicate $10 \%, 5 \%$ and $1 \%$ significant level.

\section{Conclusion and Discussion}

Recent research mostly focuses on the correlation between LME's copper prices with oil, metals, overall economic indicators and price volatility. For example, Gao and Wang [1] studied the LME's copper futures contract price and NYMEX's copper futures prices and found strong and negative asymmetries. Mabrouk [5] studied the persistence, clustering and asymmetry of LME's copper prices, and the result is consistent with the results of this study, where this study used ARCH model to examine the asymmetric effects of LME's copper futures returns on spot returns volatility. That said, discussions of volatility under highly volatile market conditions are nevertheless absent. 
This paper integrates the TAR and MTAR GARCH model as the Hybrid TAR/MTAR-GARCH model to forecast the volatility of copper returns. Meanwhile, it introduces the assessment on the simulated interaction of TAR and MTAR into average and variance formulas so as to prevent the econometrics model from generating errors. Then, it designs two random threshold values to augment the testing method of GJR-GARCH model with zero-threshold value, enabling the variance formula to test two random threshold values simultaneously.

By estimating the asymmetric threshold parameter, it is revealed that the HMTAR-GARCH model has higher explanatory power than the GJR-GARCH model. This study verifies three hypotheses. Firstly, it verifies that during highly volatile period, when the lagged residuals are lower than their thresholds, the impacts on copper returns volatility are greater. Secondly, it verifies that during highly volatile period, when the lagged residual differences are lower than momentum thresholds, the impacts on copper returns volatility are greater. Finally, results show that during highly volatile period, the MTAR effect is even greater than the TAR effect.

In conclusion, the above findings suggest that the Hybrid HMTAR-GARCH model has better level of fitness than the GJR-GARCH model, and the former is able to capture the asymmetric and nonlinear nature of copper returns volatility. In particular, it reveals the asymmetric and nonlinear momentum threshold effects of London's copper futures returns on spot returns volatility under highly volatile market conditions; hence it could facilitate the forecasting of copper spots volatility and arbitrage decision-making during a period of high volatility.

Moreover, in terms of supply and demand of copper, the HMTAR-GARCH model could help clients and suppliers set up better risk prevention strategies and obtain additional earnings from financial practices on top of operating profits. For example, global electricity and electronics sector, architectural sector, transportation industry, industrial manufacturing, retail and consumers, copper mining, copper recycling professionals and governments' infrastructure administrative departments could apply the HMTAR-GARCH model to risk management, thus enable traders and manufacturers to develop better investment and risk prevention strategies.

Although this paper attempts to derive a better threshold GARCH model for exploring better volatility forecasting model, there are some possible modifications. Firstly, the double thresholds model could be extended to multiple thresholds in mean and variance equations. Secondly, the discrete threshold model could be extended to continuous ESTAR or LSTAR-type model, which could measure continuous unexpected information threshold shocks to conditional volatility.

\section{Conflicts of Interest}

The authors declare no conflicts of interest regarding the publication of this paper. 


\section{References}

[1] Gao, A.H. and Wang, H.K. (2005) Asymmetric Volatility of Basis and the Theory of Storage. Journal of Futures Markets, 25, 399-418. https://doi.org/10.1002/fut.20144

[2] Zhu, X.H., Feng, Y.W. and Guo, Y.Q. (2015) An Empirical Study on the Effect of Financial Factors on Copper Futures Price Volatility. Journal of Central South University, 21, 124-129.

[3] Zhang, C.G. and Tu, X. (2016) The Effect of Global Oil Price Shocks on China's Metal Markets. Energy Policy, 90, 131-139. https://doi.org/10.1016/j.enpol.2015.12.012

[4] Wu, D. and Hu, Z. (2016) Structural Changes and Volatility Correlation in Nonferrous, Metal Market. Transactions of Nonferrous Metals Society of China, 26, 2784-2792. https://doi.org/10.1016/S1003-6326(16)64395-9

[5] Mabrouk, S. (2017) Volatility Modelling and Parametric Value-At-Risk Forecast Accuracy: Evidence from Metal Products. Asian Economic and Financial Review, 7, 63-80. https://doi.org/10.18488/journal.aefr/2017.7.1/102.1.63.80

[6] Wang, T.C. and Chang, S.C. (2018) On the Relationship among the U.S. Industry Index, the Raw Materials Prices and the U.S. Stock Market Volatility. Journal of Global Business Operation and Management, 10, 167-183.

[7] Fama, E.F. and French, K.R. (1988) Permanent and Temporary Components of Stock Prices. Journal of Political Economy, 96, 246-273.

https://doi.org/10.1086/261535

[8] Chatrath, A., Rohan, C.D., Dhanda, K.K. and Koch, T.W. (2002) Index Futures Leadership, Basis Behavior and Trader Selectivity. Journal of Futures Markets, 22, 649-677. https://doi.org/10.1002/fut.10026

[9] Ali, G. (2013) EGARCH, GJR-GARCH, TGARCH, AVGARCH, NGARCH, IGARCH and APARCH Models for Pathogens at Marine Recreational Sites. Journal of Statistical and Econometric Methods, 2, 57-73.

[10] Awartani, B.M.A. and Corradi, V. (2005) Predicting the Volatility of the S \& P-500 Stock Index via GARCH Models: the Role of Asymmetries. International Journal of Forecasting, 21, 167-183. https://doi.org/10.1016/j.ijforecast.2004.08.003

[11] Hentschel, L. (1995) All in the Family Nesting Symmetric and Asymmetric GARCH Models. Journal of Financial Economics, 39, 71-104. https://doi.org/10.1016/0304-405X(94)00821-H

[12] Kang, S.H. and Yoon, S.M. (2013) Revisited Returns and Volatility Spillover Effect in Korea. Korea and the World Economy, 14, 121-145.

[13] Lundbergh, S. and Teräsvirta, T. (2002) Evaluating GARCH Models. Journal of Econometrics, 110, 417-435. https://doi.org/10.1016/S0304-4076(02)00096-9

[14] Balcombe, K. and Rapsomanikis, G. (2008) Bayesian Estimation and Selection of Nonlinear Vector Error Correction Models: The Case of the Sugar-Ethanol-Oil Nexus in Brazil. American Journal of Agricultural Economics, 90, 658-668. https://doi.org/10.1111/j.1467-8276.2008.01136.x

[15] Enders, W. and Siklos, P.L. (2001) Cointegration and Threshold Adjustment. Journal of Business and Economic Statistics, 19, 166-176. https://doi.org/10.1198/073500101316970395

[16] Sjölander, P. (2013) A Ridge Bootstrap Method for Analyzing APT Effects on the Mortgage Loan Market. Economic Modelling, 30, 844-855.

https://doi.org/10.1016/j.econmod.2012.09.044

[17] Goo, Y.J. and Shih, A.Y. (2018) The Effects of an Asymmetric Momentum Thre- 
shold on the Basis Volatility-Tranquil versus Turbulent Periods. Review of Securities and Futures Markets, 30, 75-96.

[18] Dickey, D.A. and Fuller, W.A. (1981) Likelihood Ratio Statistics for Autoregressive Time Series with Unit Root. Econometrica, 49, 1057-1072. https://doi.org/10.2307/1912517

[19] Phillips, P.C.B. and Perron, P. (1988) Testing for a Unit Root in Time Series Regression. Biometrika, 75, 335-346. https://doi.org/10.1093/biomet/75.2.335

[20] Kapetanios, G., Shin, Y. and Snell, A. (2003) Testing for a Unit Root in the Nonlinear STAR Framework. Journal of Econometrics, 112, 359-379. https://doi.org/10.1016/S0304-4076(02)00202-6

[21] Enders, W. and Granger, C.W.J. (1998) Unit-Root Tests and Asymmetric Adjustment with an Example Using the Term Structure of Interest Rates. Journal of Business and Economic Statistics, 16, 304-311. https://doi.org/10.1080/07350015.1998.10524769

[22] Baur, D.G. and McDermott, T.K. (2010) Is Gold a Safe Haven? International evidence. Journal of Banking \& Finance, 34, 1886-1898.

https://doi.org/10.1016/j.jbankfin.2009.12.008

[23] Akaike, H.A. (1974) A New Look at the Statistical Model Identification. IEEE Transactions on Automatic Control, 19, 716-723. https://doi.org/10.1109/TAC.1974.1100705

[24] Schwarz, G. (1978) Estimating the Dimension of a Model. The Annals of Statistics, 6, 461-464. https://doi.org/10.1214/aos/1176344136 